\title{
A new estimate of the population size of the Critically Endangered Rodrigues fruit bat Pteropus rodricensis
}

\author{
Vicki J. Powell and Stephanie C. Wehnelt
}

\begin{abstract}
The Rodrigues fruit bat Pteropus rodricensis is endemic to Rodrigues Island, the smallest of the Mascarene Islands in the Indian Ocean. The species is categorized as Critically Endangered on the IUCN Red List. A study between February 2001 and February 2002 identified 10 roosts, four previously unrecorded. Roost sites were located in the north and south of the island, all within forested valleys. Sixteen counts of each roost site, evenly spaced throughout the study period, showed dramatic changes in individual colony numbers, suggest-
\end{abstract}

ing movement between roosts. Simultaneous counts of all colonies resulted in a minimum population estimate of 5,076, which is substantially higher than previous estimates of the species. This is believed to be due to a population increase since the last count, newly identified roosts and the movement of bats into different areas, allowing more accurate counts to be made.

Keywords Mascarene Islands, population census, Pteropus rodricensis, Red List, Rodrigues fruit bat, roosts.

\section{Introduction}

The Rodrigues fruit bat Pteropus rodricensis is endemic to Rodrigues Island in the Indian Ocean. Rodrigues Island is the smallest of the Mascarene Islands, lying $574 \mathrm{~km}$ east of Mauritius (Fig. 1a). At its greatest length and breadth it measures 18 and $8 \mathrm{~km}$, respectively. The island is generally hilly with a central ridge that rises to $400 \mathrm{~m}$ (Strahm, 1989). It has a sub-tropical climate, with a dry season during May-October and a wet season during November-April. Due to a shift in trade winds between December and April, tropical cyclones can occur over the island (Strahm, 1989). Once covered with native dense vegetation, the island is now mainly barren hillsides with small patches of secondary forest comprised mostly of exotic plant species. The most densely vegetated areas are in the valleys to the north and south of the central region, and the most barren tract of land is located to the west.

A decline in the population of $P$. rodricensis began in the 1950s and can mostly be attributed to the extensive clearance of forested areas, including many tree species utilized by the bats for food and shelter (Cheke \& Dahl, 1981). Until the mid 1970s bats were reported to be heavily hunted for food and sport (Vinson, 1964) and

Vicki J. Powell (Corresponding author) North of England Zoological Society, Chester Zoo, Caughall Road, Upton, Chester, CH2 1LH, UK. E-mail: vicki@powellbat.fsnet.co.uk and vickibat@yahoo.co.uk

Stephanie C. Wehnelt North of England Zoological Society, Chester Zoo, Caughall Road, Upton, Chester, CH2 1LH, UK.

Received 16 April 2002. Revision requested 16 September 2002. Accepted 8 April 2003. the numbers were further reduced by two severe cyclones, in 1968 and 1972, and a severe drought during 1973-1974 (Cheke \& Dahl, 1981). By 1974, numbers had fallen below 100 and the species was described as "the rarest bat in the world" (Cheke, 1974). The species is currently listed as Critically Endangered on the IUCN Red List (IUCN, 2002).

Conservation efforts began in 1976 when the Durrell Wildlife Conservation Trust caught 18 bats to start a captive breeding programme at Jersey Zoo. Breeding populations of $P$. rodricensis are now maintained at 28 zoos around the world. In situ conservation has mainly centred on restoration of the natural habitat, watershed protection and education of the local people. Bat numbers have been steadily increasing since 1974, although with two notable declines, in 1979 and 1991, due to the effects of cyclones (Mungroo, 1979; C. Jones, pers. comm.). Cyclones appear to have had a devastating effect on the population, with mortality rates of up to $50 \%$ (Mungroo, 1979). Lack of forest cover renders the bats susceptible to the high wind speeds that sometimes exceed $100 \mathrm{mph}$. However, the secondary effects of food shortage and dehydration appear to be even more severe (C. Jones, pers. comm.). Table 1 shows the population estimates for the species from 1955 to 1998. Although population numbers have slowly increased during this period, $P$. rodricensis still remains one of the highest conservation priorities among the Old World fruit bats and there are still many deficiencies in our knowledge of the species. (Mickleburgh et al., 1992). The main objectives of this study were to identify all roosting sites on the island and to obtain a reliable population estimate for the species. 

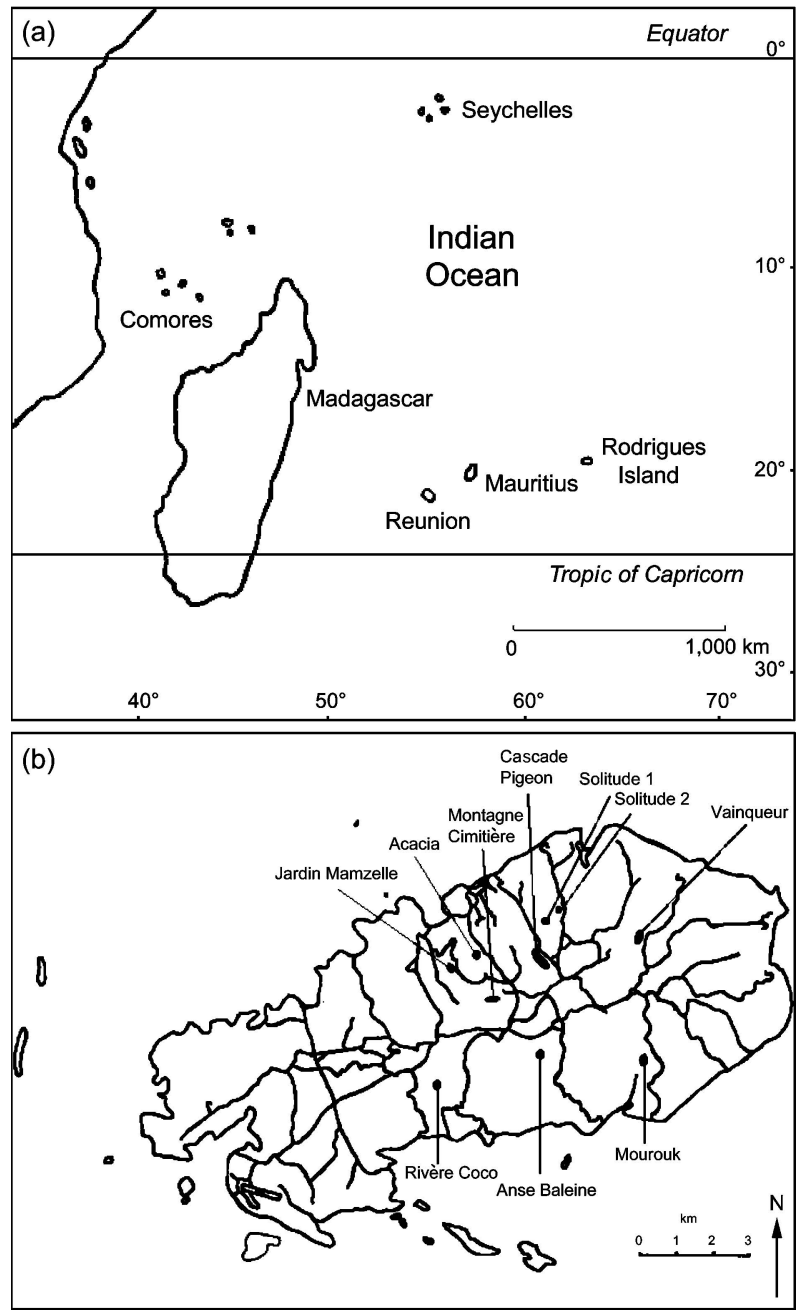

Fig. 1 (a) The location of Rodrigues Island in the Indian Ocean. (b) The locations of the 10 roost sites of Pteropus rodricensis on Rodrigues Island (adapted from Strahm, 1989).

\section{Methods}

We conducted a survey between February 2001 and February 2002, with c. 200 days spent in the field. With the aid of 12 staff from the Mauritian Wildlife Foundation, all 24 of the forested valleys across the island were surveyed for bat roosts. If the entire valley was visible from one point, the area was surveyed from this viewpoint from 16.00 until darkness, watching for any emerging bats. If the valley was too large to be viewed from one position, several observers were placed at different points in the valley to ensure all areas were surveyed from 16.00 until darkness. At each survey site local villagers were interviewed to obtain more knowledge about bat localities.

All roosts, with the exception of the colony at Solitude 1 (Fig. 1b), were counted using Evening Dispersal Counts
Table 1 Population estimates for Pteropus rodricensis 1955-1998

\begin{tabular}{lll}
\hline Year & Estimated population size & Reference \\
\hline 1955 & $1,000+$ & Cheke \& Dahl, 1981 \\
1965 & $200+$ & Cheke \& Dahl, 1981 \\
1974 & $69+$ & Cheke, 1974 \\
1975 & $70+$ & Cheke \& Dahl, 1981 \\
1976 & $130+$ & Durrell, 1976 \\
1978 & 151 & Cheke \& Dahl 1978 \\
1979 & 70 (Post Cyclone Celine II) & Mungroo, 1979 \\
1981 & 200 & Carroll, 1981 \\
1982 & $300-350$ & c. Jones unpub. data \\
1988 & 412 & Young, 1988 \\
1991 & $800-950$ & c. Jones unpub. data \\
1991 & $400-600$ (Post Cyclone Bella) & c. Jones unpub. data \\
1995 & $550+$ & Whitman, 1995 \\
1997 & 1,200 & Whitman, 1998 \\
1998 & $1,500-2,000$ & Jones, 1998 \\
\hline & &
\end{tabular}

(EDCs) (Racey, 1979). Lack of viewpoints overlooking the Solitude roost precluded the use of EDCs and the colony was counted in the early morning when the bats were at their most conspicuous (Jones, 1998). At this site a set route was walked beneath the roost trees and the number of visible bats was recorded. Daytime colony counts were tried at every roost but they appeared to dramatically underestimate bat numbers (Racey, 1979; Nicoll \& Racey, 1981; Lemke, 1992). Sixteen evenly spaced counts were conducted at all sites throughout the field seasons. EDCs were carried out from a location with a clear view over the roost and a tally counter was used to monitor the number of bats leaving the site. Bats leaving the main roosting area were recorded every $5 \mathrm{~min}$. Any bats returning to this area were recorded separately every $5 \mathrm{~min}$. It was assumed that these returning bats had circled back into the roost and they were therefore subtracted from the total. The number of bats that remained in the valley was recorded as well as the number leaving and the direction of flight. If any bats entered the valley from other roost sites, their number and direction of origin were noted.

A slightly different counting method was used for the bats roosting at Cascade Pigeon (Fig. 1b) where three large roost sites are found spread along the eastern side of the valley and where normal EDCs were not possible. Since 2000, counts at this site have been carried out weekly as the bats fly south out of the valley over Malabar (C. Jones, pers. comm.).This roost was counted by the Mauritian Wildlife Foundation team every week.

In addition to these individual counts, a simultaneous count of all roost sites was carried out on eight occasions, with two observers stationed at the standard counting position at each roost site. Methods were identical to those stated above. 


\section{Results}

Bats were located at previously identified roost sites at Cascade Pigeon, Solitude, Jardin Mamzelle, Acacia, Montagne Cimitière and Mourouk (Jones, 1998). Three additional sites were identified at Anse Baleine, Vainqueur and Rivière Coco and a new roost site formed at Solitude during January 2002 (Fig. 1b). Direct observations and reports from local people helped identify a number of valleys as locations for bat roosts at certain times of the year. These temporary roosts were apparently present when mango Mangifera indica was fruiting and after severe cyclones had hit the island.

In all a total of 10 roost sites were located to the north and south of the central region of the island (Fig. 1b). Seven roosts were found to the north, the majority in valleys oriented north-west. In all of these sites bats roosted on the eastern slope of the valley. The three roosts on the southern part of the island were all oriented south; two had roosts on the eastern slope of the valley and one on the west. The majority of roost areas were located on valley sides, with the exception of the roosts at Solitude, which is in a less topographically complex area.

Over the study period the highest percentage of bats were found in four roosts in the north of the island: Montagne Cimitière, Vainqueur, Cascade Pigeon and Jardin Mamzelle. Between 1 and 9\% of the total population were found in the other five roosts. The number of bats at each site ranged from 11 to 1,965 (median 187). Four of the roost sites exhibited large changes in numbers. Jardin Mamzelle decreased from 1,526 to just 25 individuals; Montagne Cimitière increased from 167 to 1,965 and Vainqueur increased from 277 to 1,190 . The roost at Cascade Pigeon showed fluctuations throughout the study period with a lowest count of 242 and a highest of 1,662 .

Previous bat censuses have always shown a high percentage of the population roosting at Cascade Pigeon
(Carroll, 1981; Whitman, 1995; Jones, 1998; C. Jones, pers. comm.). However, because it is only possible to count the bats as they leave the valley, it is difficult to know how many individuals remain within the valley to feed. Towards the end of the study period, the forestry department began to thin the forest area of Cascade Pigeon by removing exotic species and planting endemic species. The disturbance caused by the felling within this area led to a large movement of bats out of this site into areas where more accurate counts could be made. Subsequent counts at Cascade Pigeon showed less than 300 individuals and the roost sites at Montagne Cimitière and Vainqueur increased to 1,965 and 1,190 respectively. A simultaneous count of all roosts at this time gave a total population estimate of 5,076 bats (Table 2). Previous simultaneous counts during this study gave lower estimates of between 2,497 and 3,842 (Table 2) coinciding with the majority of bats roosting within Cascade Pigeon or poor weather conditions during counts.

\section{Discussion}

With all valleys on the island surveyed, it is highly unlikely that any permanent colonies of Pteropus rodricensis have been overlooked. The newly identified roost sites were found during the valley searches and by contacting local communities. Talks with community elders established that the bats had been permanently resident at Vainqueur since 1981 when the local people had moved their homes out of the forest area. The two southern roosts at Anse Baleine and Riviere Coco have, according to local foresters, been occupied by bats for a minimum of 4 years. Because these roost sites were not included in previous surveys, counts of the bat colonies may have given a misleading estimate of the size of the population. A second roost was formed at Solitude in January 2002. This is believed to be related to the movement of bats out of the Cascade Pigeon roost during the period when trees were being felled in the valley.

Table 2 Simultaneous counts of Pteropus rodricensis at 10 roosts during the period February 2001 to February 2002

\begin{tabular}{|c|c|c|c|c|c|c|c|c|}
\hline Roost Site & $\begin{array}{l}\text { March } \\
2001\end{array}$ & $\begin{array}{l}\text { April } \\
2001\end{array}$ & $\begin{array}{l}\text { May } \\
2001\end{array}$ & $\begin{array}{l}\text { Oct. } \\
2001\end{array}$ & $\begin{array}{l}\text { Nov. } \\
2001\end{array}$ & $\begin{array}{l}\text { Dec. } \\
2001\end{array}$ & $\begin{array}{l}\text { Jan. } \\
2002\end{array}$ & $\begin{array}{l}\text { Feb. } \\
2002\end{array}$ \\
\hline Cascade Pigeon & 1,662 & 1,608 & 1,350 & 495 & 333 & 673 & 935 & 342 \\
\hline Acacia & 409 & 290 & 262 & 431 & 114 & 284 & 309 & 250 \\
\hline A. Baleine & 323 & 241 & 122 & 138 & 65 & 89 & 299 & 230 \\
\hline Vainqueur & 312 & 214 & 324 & 284 & 824 & 713 & 1,353 & 677 \\
\hline Rivière Coco & 251 & 187 & 142 & 60 & 39 & 69 & 30 & 86 \\
\hline Mourouk & 214 & 277 & 200 & 155 & 63 & 41 & 38 & 152 \\
\hline Jardin Mamzelle & 209 & 380 & 469 & 907 & 746 & 359 & 104 & 190 \\
\hline Montagne Cimitière & 52 & 133 & 36 & 190 & 775 & 1,450 & 1,823 & 342 \\
\hline Solitude 1 & 24 & 36 & 42 & 65 & 51 & 164 & 32 & 33 \\
\hline Solitude 2 & & & & & & & 153 & 195 \\
\hline Total & 3,456 & 3,366 & 2,947 & 2,725 & 3,010 & 3,842 & 5,076 & 2,497 \\
\hline
\end{tabular}


Forests appear to provide the only roosting habitat for the species. All colonies were found to the north and south of the central region of Rodrigues, the area that comprises most of the forested valleys. With the exception of Anse Baleine, all roost sites were located on the eastern slope of the valley thus providing the essential protection needed from the south-east trade winds. On the eastern side of the valley at Anse Baleine much of the forest had been cut down, whereas the western side is densely forested and steep. If this roost has only been occupied for the last 4 years, the bats here will not yet have experienced a major cyclone and the site may not offer as much protection as other areas.

Although all roost sites were counted individually within a limited period of time, a total population estimate cannot be derived from this due to the possible movement between sites. However, certain colonies did show a notable change in size throughout the study period. It seems possible that the decrease in size of the Jardin Mamzelle colony may be linked to the increase at Montagne Cimitière, considering the sites are in close proximity. Although EDCs were the most accurate way of monitoring the colony size at each roost, some errors might have occurred. For each count, the number of bats leaving the roost formed a normal distribution curve, however, it was clear that some individuals still remained within the roost trees after darkness. Taking this into account, all counts can only be classed as a minimum estimate of the true colony size.

The counts at Cascade Pigeon have been shown to be highly variable since they first began in 1982 (C. Jones, pers. comm.). A preliminary assessment of food availability within the valley suggests that count variation may be caused by changes in spatial and temporal patterns of plant fruiting and flowering, with more bats remaining within the valley when there is a plentiful supply of food (V. Powell, unpub. data). Consequently, while this area remained the main bat roost site, an accurate simultaneous count of the population proved to be difficult. The movement of bats to forest patches where clear counts could be made as they left their roost trees, as opposed to emergence counts from the top of the valley at Cascade Pigeon, has led to a more accurate total estimate of the population. Variable counts can also be attributed to poor weather conditions. Lower simultaneous counts were always recorded during wet and windy conditions, when bats tended to remain in their roosts for a longer period of time after dusk.

In conclusion, this study shows that the population of $P$. rodricensis on Rodrigues is higher than previously estimated. Four new colonies have been identified, and the population is distributed over a wider area than previously reported. However, the possibility of a dramatic population decline in the future still exists, given the known impacts of cyclones on bats (Mungroo, 1979; C. G. Jones, pers. comm.). Future work is planned as part of ongoing research to provide better information on which to base in situ and ex situ conservation management of $P$. rodricensis.

\section{Acknowledgements}

We would like to thank Drs Barry Stevens-Wood and Martin Jones for their valuable input into the design of this project. This work could not have been carried out without the financial and practical support of the North of England Zoological Society. Bat Conservation International, Air Mauritius and the American Zoo and Aquarium Association Bat Taxon Advisory Group are also gratefully acknowledged for their financial support. Useful advice and field assistance were provided by the Mauritian Wildlife Foundation, in particular Dr. Carl Jones, Richard Payandee, the Rodrigues wildlife team and the Rodrigues forestry department. We are very grateful to Professor Rory Putman and Dr. Bryan Carroll for their comments on a draft manuscript.

\section{References}

Carroll, J.B. (1981) The wild status and behaviour of the Rodrigues fruit bat Pteropus rodricensis. A report of the 1981 field study. Dodo, Journal of the Jersey Wildife Preservation Trust, 18, 20-29.

Carroll, J.B. (1988) The conservation programme for the Rodrigues fruit bat Pteropus rodricensis. In Proceedings of the Fifth World Conference on Breeding Endangered Species in Captivity (eds B.L. Dresser, R.W. Reece \& E.J. Maruska), pp. 457-475, Cincinnati Zoo and Botanical Gardens, Cincinnati, USA.

Cheke, A.S. (1974) Report on Rodrigues. British Ornithologists Union Mascarene Islands Expedition. Unpublished Report.

Cheke, A.S. \& Dahl, J.S. (1981) The status of bats on the western Indian Ocean Islands with special reference to Pteropus. Mammalia, 45, 205-238.

Durrell, G.M. (1976) The Mauritian expedition. Jersey Wildlife Preservation Trust Annual Report, 13, 7-11.

IUCN (2002) 2002 IUCN Red List of Threatened Species. IUCN, Gland, Switzerland [http:/ / www.redlist.org, accessed 6 April 2003]

Jones, V. (1998) A population study of the Rodrigues Fruit Bat Pteropus rodricensis. MSc thesis, University of Kent, Canterbury, UK.

Lemke, T.O. (1992) Status of the Marianas fruit bat (Pteropus mariannus) in the Northern Mariana Islands north of Saipan. In Pacific Island Flying Foxes: Proceedings of an International Conservation Conference (eds D.E. Wilson \& G.L. Graham), pp. 68-73. US Fish and Wildlife Service Biological Report, 90(23), US Department of the Interior, Fish and Wildlife Service, Washington, DC, USA. 
Mickleburgh, S.P., Hutson, A.M. \& Racey, P.A. (1992). Old World Fruit Bats. An Action Plan for their Conservation. IUCN, Gland, Switzerland.

Mungroo, Y. (1979) Report of Post Cyclone Celine II Survey of the Endemic Passeriformes, Bats and Seabirds of Rodrigues. Unpublished report, Forestry Department, Curepipe, Mauritius.

Nicoll, M.E. \& Racey, P.A. (1981) The Seychelles fruit bat, Pteropus seychellensis. African Journal of Ecology, 19, 361-364.

Racey, P.A. (1979) Two bats in the seychelles. Oryx, 15, 148-152.

Strahm, W.A. (1989) Plant Red Data Book for Rodrigues. Koeltz Scientific Books, Konigstein, Germany.

Vinson, J. (1964) Quelques remarques sur l'Ile Rodrigue et sur sa faune terrestre. Proceedings of the Royal Society of Arts and Sciences, Mauritius, 2, 263-277.

Whitman, K.L. (1995) Preliminary report on the study of the biology of the Rodrigues fruit bat (Pteropus rodricensis) and the associated primary school education program. In Rodrigues Fruit Bat, Pteropus rodricensis, International Studbook (eds J.B. Carroll, L. Gilmour \& S. Courts), pp. 8-12. Jersey Wildlife Preservation Trust, Jersey, Channel Islands, UK.

Whitman, K.L. (1998) Control region sequence divergence within and between wild and captive populations of Rodrigues fruit bats Pteropus rodricensis: implications for conservation and management. MSc thesis, Villanova University, Villanova, USA.
Young, H.G. (1988) Birds of Mauritius, with Notes on other Vertebrates and the Islands of Rodrigues and Reunion.

Unpublished Report to Jersey Wildlife Preservation Trust.

\section{Biographical sketches}

Vicki Powell's research interests include conservation biology, animal behaviour and the ecology of endangered animal populations, in particular bats of the genus Pteropus. She is currently continuing her studies of the conservation and ecology of Pteropus rodricensis.

Dr. Stephanie Wehnelt is a behavioural ecologist involved in a wide variety of research projects. In the field of conservation, Stephanie contributes to numerous captive breeding programmes and acts as scientific adviser in the harvest mouse release programme of Chester Zoo, UK.

\section{Postscript}

On 12 March 2003 cyclone Kalunde hit Rodrigues. The effects of the cyclone on the bats and their habitat are being monitored. 